\title{
Side-branching in the mammary gland: the progesterone-Wnt connection
}

\author{
Gertraud W. Robinson, ${ }^{1}$ Lothar Hennighausen, and Peter F. Johnson ${ }^{2}$ \\ Laboratory of Genetics and Physiology, National Institute of Diabetes and Digestive and Kidney Diseases, National \\ Institutes of Health, Bethesda, Maryland 20892-0822 USA; ${ }^{2}$ Eukaryotic Transcriptional Regulation Section, Regulation \\ of Cell Growth Laboratory, National Cancer Institute-Frederick Cancer Research Development Center (FCRDC), Frederick, \\ Maryland 21702-1201 USA
}

The mammary gland is a derivative of the ectoderm whose development begins in the embryo and progresses after birth. The major part of development occurs in the adolescent and adult animal. Hormones produced by the pituitary, the ovaries, the uterus, the placenta, and the mammary gland itself control this process. Over the past century, surgical, biological, and genetic tools have been used to gain insight into physiological and pathological processes in the mammary gland. Originally, endocrine ablation and reconstitution experiments provided a descriptive framework of the role of ovarian and pituitary hormones (Halban 1900; Nandi 1958). These experiments demonstrated a clear requirement for the ovarian steroids estrogen and progesterone for ductal growth and alveolar development (Topper and Freeman 1980). In prepubescent mice the gland consists of a small ductal tree that emanates from the nipple into the proximal part of the fatty stroma, the mammary fat pad (Fig. 1). Upon initiation of ovarian hormone secretion, the mammary epithelium enters an accelerated growth phase that leads to extension and branching of the ducts until they reach the limits of the fat pad. In response to changing levels of estrogens and progestins during each estrous cycle, alveolar buds are formed from the lateral walls of the ducts and lost again. At the onset of pregnancy extensive epithelial cell proliferation occurs, leading to formation of lobulo-alveolar structures and secretory epithelial differentiation. These morphogenetic and cellular responses are controlled by signaling cascades initiated by progesterone (Lydon et al. 1995), placental lactogens, and prolactin (Horseman et al. 1997; Ormandy et al. 1997).

More recently, the availability of transgenic and gene knockout mice has provided genetic handles to investigate the contribution of the different hormones to the regulation of cell growth, differentiation, and death in the gland, and to dissect the corresponding signaling pathways. Using such gene knockout mice Brisken and colleagues (Brisken et al. 2000) have now been able to link progesterone and Wnt signaling to the branching of

${ }^{1}$ Corresponding author.

E-MAIL gertraur@bdg10.niddk.nih.gov; FAX (301) 480-7312. mammary ducts during puberty and pregnancy. Their studies demonstrate that a nuclear signal is converted into a secreted signal that can control the fate of adjacent cells in a paracrine fashion. A genetic understanding of this and other signaling pathways regulating cell growth in the mammary gland will improve our ability to manipulate these processes and thus design strategies for prevention and treatment of breast cancer.

\section{Tools to investigate signaling pathways}

Several features of the mammary gland provide unique opportunities for experimental manipulations to integrate systemic, local and cell-specific signaling pathways. Mice with deletions of different genes have been a powerful tool to investigate the respective pathways (Hennighausen and Robinson 1998). However, although the analysis of null mutants created by standard embryonic stem cell-based homologous recombination can provide valuable information on signaling pathways, this approach may fail to address the complexities underlying development of the mammary gland. It is now possible to delete genes in specific cell types and thus define their roles in different compartments (Xu et al. 1999). This technique also bypasses problems encountered with preand perinatal lethality and infertility. The power of genetically engineered mice is further enhanced through the use of sophisticated surgical techniques that permit the separation of stromal and epithelial signals. Removal of the epithelium-containing proximal portion of the gland at 3 weeks of age renders an epithelium-free fat pad, which can be implanted with exogenous epithelial cells, resulting in a chimeric gland composed of tissues of different origins (DeOme et al. 1959). In this manner the signaling between epithelium and stroma, a defining aspect of organogenesis, can be evaluated. This approach also circumvents fertility problems and allows one to distinguish primary, cell autonomous defects of a mutation from secondary, systemic hormone effects. This is particularly important in cases where a mutation also affects the ovary in addition to the mammary gland (Robinson et al. 1998). Another unique feature of the mammary epithelium, which can be applied to investigate 
Figure 1. (A) Whole-mount analysis of mammary tissue from 4-week-old virgin $(a)$, 10-week-old virgin $(b)$, day 11 pregnant $(c)$, and lactating $(d)$ mice. (LN) Lymph node. All pictures are taken at the same magnification. (B) Schematic drawings of the mammary fat pad and ductal and alveolar development. A simple ductal tree occupies the fat pad in the immature virgin. The fat pad is filled in mature virgins and substantial side-branching has taken place. Alveolar development occurs during pregnancy and is completed during lactation. Proteins that control defined stages of mammary development (as determined in gene knockout mice) are shown below the corresponding developmental stage. The arrows indicate likely genetic pathways. Although c-myc expression is induced by progesterone, it is not clear whether this occurs in MECs. Downstream targets of Stat $5 \mathrm{a}$ and C/EBP $\beta$ in mammary tissue are not

A

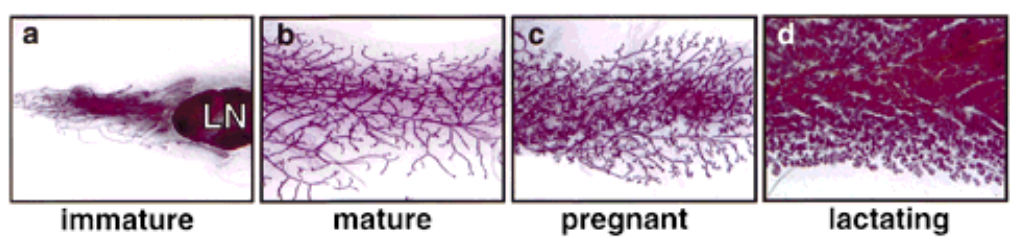

B

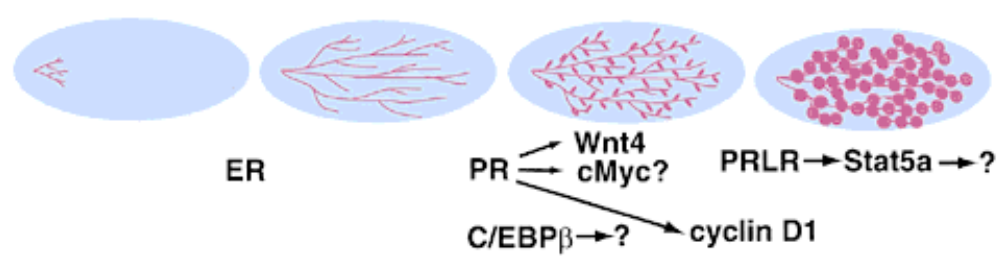

known. (ER) Estrogen receptor; (PR) Progesterone receptor; (PRLR) Prolactin receptor. The images are deposited at the NIH HistoBank (http://histology.nih.gov) and can be viewed under the following accession nos.: mammary tissue from an immature virgin, 1345; mammary tissue from a mature virgin, 1346; mammary tissue from day 11 of pregnancy, 1347; mammary tissue from lactation, 1348.

cell-cell interactions and paracrine signaling, is its large capacity for regeneration. Each portion of the ductal system contains stem cells that are capable of regenerating an entire epithelial tree upon transplantation (Kordon and Smith 1998). By mixing epithelial cells of different origins prior to transplantation, it is possible to create chimeric secretory epithelia in mice. Introducing a tag that can be visualized, such as the lac $Z$ gene, into one of the epithelial components makes it possible to identify the origin of individual cells in such mixed epithelial transplants. This is of particular importance in the investigation of paracrine interactions between individual epithelial cells. Finally, the ability of embryonic and neonatal mammary tissue to develop a full mammary gland upon transplantation into cleared fat pads of adult mice provides the opportunity to investigate gene function in lethal knockout mice (Robinson et al. 2000). Unlike the Cre/LoxP approach, in which a gene is deleted in the epithelium at a time determined by the transgene, this approach evaluates the outgrowth and development of mutant epithelium.

\section{The progesterone-Wnt connection}

More than 100 years ago, Halban observed that ovaries are required for functional development of the mammary gland (Halban 1900). As we know now, estrogen and progesterone are the controlling factors. Whereas estrogen is required for development of the primary ductal system, progesterone controls alveolar budding and development during puberty and pregnancy. Progesterone had been implicated as a mitogen for mammary epithelial cells (MECs), which was confirmed in progesterone receptor (PR)-null mice that exhibited impaired branching and alveolar budding (Lydon et al. 1995). Two PR isoforms (A and $\mathrm{B}$ ) derived from the same gene by different promoters have been identified, but their specific functions are not understood. Perturbation of their ratio by overexpression of the A form causes aberrant ductal morphology, more extensive lateral branching, and hyperplasia, an indication of the involvement of PR in mammary epithelial proliferation (Shyamala et al. 1998).

Although it was clear for some time that the PR is required for branching and budding (Lydon et al. 1995), little was known about downstream mediators. The first tip-off that secreted signals conveyed the steroid information came from cell mixing experiments. Brisken, Weinberg, and their colleagues demonstrated that PRnull MECs (tagged with the ROSA26 lacZ marker) could form alveolar-like structures after grafting into cleared fat pads when mixed with PR-containing MECs (Brisken et al. 1998). Tissue recombination experiments further demonstrated that the stroma did not contribute to the growth signaling. Based on these results, a paracrine mechanism of PR action confined to epithelial cells was proposed. A recent paper by Brisken and colleagues now solves part of this puzzle and identifies Wnt-4 as a likely mediator of this signal (Brisken et al. 2000).

\section{Signaling through Wnt}

Wnts are a family of secreted, cysteine-rich glycoproteins that function as short-range signaling factors. Wnt proteins are associated with the cell surface and extracellular matrix (Parkin et al. 1993; Schryver et al. 1996) and, as such, their effects tend to be spatially localized. The first mammalian Wnt gene, originally termed Int-1, was identified at a site of murine mammary tumor virus (MMTV) integration in mammary tumors (Nusse and Varmus 1982). The Int-1 gene exhibited homology to wingless (wg), a Drosophila segment polarity gene, and subsequently the name Wnt was chosen for members of this family. At least sixteen mammalian Wnt genes have been identified, several of which are expressed in mammary tissue (see below). Wnt proteins elicit a variety of cellular responses, including proliferation, differentia- 
tion, and morphogenesis, and control developmental decisions such as axis formation in Xenopus embryos (Moon et al. 1997). Indeed, Wnts are now recognized as one of the major classes of signaling proteins that regulate development and cell fate in multicellular organisms. Several excellent reviews have been written on the subject and readers are referred to these articles for more details (Nusse and Varmus 1992; Cadigan and Nusse 1997; Moon et al. 1997; Dale 1998; Nusse 1999|. Here we shall only briefly summarize the major Wnt signaling pathway that has been proposed from genetic studies in Drosophila and Caenorhabditis elegans, and molecular experiments performed in vertebrate systems.

The action of Wnts on target cells is mediated by binding to the frizzled (Fz) group of transmembrane receptors, of which there are at least eight members in mammals. The immediate downstream component of the signal transduction pathway is disheveled (Dsh), an intracellular protein that may directly interact with $\mathrm{Fz}$ receptors. The target of Dsh is glycogen synthase kinase-3 (GSK-3), which is homologous to the Drosophila protein encoded by zeste-white3. GSK-3 is believed to be constitutively active and functions to inhibit the Wnt pathway in the absence of Wnt signals. GSK-3 phosphorylates $\beta$-catenin, which enhances $\beta$-catenin turnover by a ubiquitin-mediated degradation pathway. In response to Wnt signals, GSK-3 activity is inhibited, leading to stabilization of the $\beta$-catenin protein. One of the targets of $\beta$-catenin is the transcription factor TCF, an HMG-box DNA-binding protein. Multiple TCF family members exist in mammals, including TCF-1, LEF-1, TCF-3, and TCF-4. $\beta$-Catenin forms a complex with TCF, converting it from a transcriptional repressor to an activator and thereby stimulating the expression of target genes. Although the genes in mammalian cells that are activated by TCFs in response to Wnt signaling are not well characterized, the c-myc proto-oncogene is one target that may mediate proliferative responses to Wnt signals (He et al. 1998).

\section{Wnts and mammary gland development}

The observation that Wnt-1 and Wnt-3 were activated by a MMTV provirus in virus-induced mammary carcinomas suggested that Wnt signaling can control the growth and differentiation of MECs. Although neither of these genes turned out to be expressed in the normal mammary tissue, other Wnt genes are expressed and differentially regulated during mouse mammary gland development (Gavin and McMahon 1992; Buhler et al. 1993; Huguet et al. 1994; Olson and Papkoff 1994; Weber-Hall et al. 1994; Lane and Leder 1997). Wnt-4, Wnt-5b, Wnt-6, $W n t-7 b$, and Wnt-10b transcripts are detected in the epithelial compartment at various stages of development. Wnt-4, Wnt-5b, and Wnt-6 mRNAs are induced during pregnancy and decrease after lactation has commenced. $W n t-10 b$ expression occurs beginning at very early stages in the mammary rudiment and continues into puberty (Lane and Leder 1997). Wnt-2, Wnt-5a, and Wnt-6 are detected in stroma at a stage preceding ductal outgrowth (Webber-Hall et al. 1994) raising the possibility that one or more of these Wnt family members are candidates for mediating epithelial induction by the stroma. At present, however, specific functions in mammopoiesis have yet to be demonstrated.

Experiments to address Wnt function in MECs have involved primarily ectopic expression of Wnt genes, either in transgenic mice or by making use of recombinant retroviruses to infect cultured epithelial cells followed by transplantation into cleared fat pads of recipient females. Transgenic mice containing the Wnt-1 gene under control of the MMTV-LTR exhibited a hyperplastic epithelial phenotype (Tsukamoto et al. 1988). The ducts of virgin animals displayed side-branching that had some resemblance to that of early to midpregnant females. The effects on mammary epithelium were also observed in males, indicating that Wnt-1 can override the female hormonal requirements for at least some aspects of ductal morphogenesis. The role of another Wnt gene, Wnt-4, in promoting ductal morphogenesis was examined using retroviral gene transfer into MECs and tissue reconstitution from the modified cells (Bradbury et al. 1995; Edwards 1998). Implanted epithelial cells expressing ectopic Wnt-4 formed ducts with extensive side-branching that was reminiscent of the branching seen in glands of pregnant animals. Indeed, Wnt-4 caused ductal arborization that more closely mimicked the structures in glands of normal pregnant mice than did Wnt-1-expressing tissue, supporting the notion that Wnt-4 may be the physiological signal that stimulates ductal morphogenesis during pregnancy.

\section{Progesterone activates paracrine Wnt signaling}

Although the aforementioned properties of Wnt-4 indicated that this factor may be involved in hormonally induced morphogenesis of the mammary gland during pregnancy, direct proof of this hypothesis required genetic analysis of mice carrying a targeted disruption of the Wnt-4 gene. This approach, however, was complicated by the fact that Wnt-4-deficient mice die perinatally as a result of renal failure (Stark et al. 1994), which precluded any direct assessment of Wnt-4 function in postnatal development of the mammary gland. The experiments by Brisken et al. (2000) now demonstrate convincingly the contribution of Wnt signaling in mediating the morphogenetic response of mammary epithelium to hormonal cues received by the mammary gland during pregnancy. Specifically, their studies link the progesterone signal, acting via its nuclear PR in epithelial cells, with expression of the Wnt-4 gene, whose product then serves as a paracrine signal to induce ductal side-branching.

To elucidate a connection between Wnt and progesterone in ductal side-branching, mice were generated that either contained or lacked a functional $P R$ gene but expressed the MMTV Wnt-1 transgene. To ensure normal PR function in other tissues, mammary epithelium from these mice was transplanted into cleared fat pads of $\mathrm{PR}^{+/+}$recipients. Compared to control transplants, increased side-branching was observed in the ducts of 
MMTV Wnt $-1^{t g}$ transplants, irrespective of whether the graft expressed a functional PR protein. These findings demonstrated that Wnt signaling functions downstream of PR. Wnt- 1 acts in a paracrine fashion to induce branching, as shown by transplanting MECs derived from MMTV Wnt- $1^{\text {tg }}$ mice, together with MECs from ROSA 26 mice, which express a lacZ transgene. Bluestained wild-type cells that were adjacent to unstained (i.e., Wnt-1-expressing) tissue in the chimeric transplants also exhibited increased side-branching, demonstrating that the Wnt-1 protein can act over short distances to elicit morphogenetic effects in nonexpressing cells.

The key experiment to assess the role of Wnt-4 involved transplanting mammary buds from $W n t-4^{-/-}$embryos into wild-type recipients and evaluating the ductal structures that developed in virgin and pregnant animals. No defects were apparent in transplants analyzed in virgin mice, demonstrating that Wnt-4 is dispensible for development of the ductal tree preceding pregnancy. However, when analyzed at day 12 of pregnancy, the mutant implants displayed reduced branching in comparison to wild-type grafts, as would be expected if Wnt-4 functions as the morphogenetic signal mediating the response to pregnancy hormones. The link between hormonal signals and Wnt-4 expression came from in situ hybridization experiments that colocalized $P R$ and Wnt-4 transcripts in luminal epithelial cells. Furthermore, Wnt-4 expression was induced by progesterone in ovariectomized animals, and Wnt-4 RNA levels were reduced in $P R^{-1-}$ epithelium. These experiments show that progesterone/PR activates expression of the Wnt-4 gene, although it remains to be established whether this occurs by a direct or indirect mechanism. In this regard, it will be important to determine whether the Wnt-4 promoter contains binding sites for PR that mediate progesterone-induced transcriptional activation.

The Brisken study resolves some previous questions, while at the same time raises other important issues. For instance, what are the roles of other Wnt genes that are expressed in mammary epithelium? Wnt-5b and Wnt-6, which are induced in epithelium during pregnancy, apparently do not substitute for Wnt-4 in eliciting ductal side-branching at day 12 of pregnancy. However, at later stages of pregnancy branching was observed in Wnt-4deficient glands, suggesting that other Wnts may become expressed and mimic the morphogenetic effects of Wnt4. Whether Wnt-5b and Wnt-6 are likely candidates for this activity is unclear, since neither factor significantly induced branching morphogenesis in retroviral gene transfer/transplantation experiments (Bradbury et al. 1995). Many of the transgenic and retroviral studies merely evaluate mammary structures on the level of whole mounts, and it is necessary to assess functional differentiation using molecular markers, such as milk proteins. Another issue concerns the functions of Wnt genes expressed in the stromal compartment. It is not known whether they have a role in inducing ductal outgrowth or branching. Answers to these questions should be forthcoming as knockout mice are generated for additional members of the Wnt family.

Although Wnt-1 can elicit ductal side-branching, its morphogenetic effects are not identical to those of Wnt4, the natural inductive signal in mammary epithelium. Moreover, Wnt genes differ in their capacity to transform C57MG MECs (Wong et al. 1994). Wnt-1, Wnt-3a, and Wnt-7 are strongly transforming, Wnt-5b, Wnt-6, and Wnt-7b display low but detectable transforming activity, and Wnt-4 and Wnt-5a, which are normally expressed in these cells, do not induce transformation. Similarly, different responses to individual Wnts were observed in stably transfected and transplanted HC11 cells, a clonal mammary epithelial cell line derived from a mid-pregnant mouse mammary gland (Humphreys and Rosen 1997). Thus, the various Wnt family members can exert differential effects on the growth and morphogenesis of MECs. These observations prompt questions about the basis of the Wnt signaling specificity. It will be instructive to determine which $\mathrm{Fz}$ receptors are expressed on MECs, as different Wnts might bind to distinct receptors. Alternatively, Wnts could activate different signaling pathways through the same receptor, perhaps by differential interactions with coreceptor proteins, and thereby elicit unique cellular responses.

\section{The genetics of budding and branching}

The progesterone-Wnt pathway is only one of the parallel, and perhaps interconnected, signaling cascades that control the formation of the ductal tree and lobulo-alveolar compartment. In the absence of prolactin or its receptor, reduced ductal side-branching has been noted. Other genes have been identified whose elimination also affects mammary gland development, in particular, the prolactin receptor (Ormandy et al. 1997) and cyclin D1 (Fantl et al. 1995; Sicinski et al. 1995). The transcription factor C/EBP $\beta$ controls fundamental aspects of cell fate and ductal branching in the mammary gland, and its function is autonomous to the epithelium (Robinson et al. 1998; Seagroves et al. 1998). C/EBP $\beta$-null mice display little ductal outgrowth, branching and alveolar budding, and expression of milk protein genes is almost entirely lacking. A recent paper by Seagroves and colleagues (Seagroves et al. 2000) now makes a connection between $C / E B P \beta$ and the PR. These authors showed that the rather uniform expression pattern of $P R$ in the immature virgin switches to a scattered expression pattern as branching and budding is initiated. Interestingly, in their study only PR-negative but not PR-positive cells underwent cell division during this inductive process. In C/EBP $\beta$-deficient glands PR expression was not extinguished and proliferation and branching was impaired. These results suggest that a selective, C/EBP $\beta$ dependent loss of PR enables a specific population of cells to respond to paracrine signals and enter the proliferative phase. At this point it is not clear whether the forced expression of Wnt-1 could bypass this block, or whether a lack of $\mathrm{C} / \mathrm{EBP} \beta$ prevents a response to Wnt signals. In addition, it is now important to establish whether ex- 
pression of Wnt genes, especially Wnt-4, is impaired in the $\mathrm{C} / \mathrm{EBP} \beta$ null mutant.

Based on the available evidence we can predict a network of signaling pathways that first determines the fate of epithelial cells and subsequently induces branching and budding through the actions of nuclear and secreted signals (Fig. 2). Although there is no doubt that progesterone signaling is mandatory for ductal branching, there is a continuing debate about which cells divide to form side-branches. Seagroves and colleagues suggest that PR is present uniformly in ductal cells prior to puberty and that selective loss of this protein occurs at puberty, followed by proliferation of PR-negative cells. In this model, Wnt would be a paracrine cell proliferation signal. Other investigators have shown that PR-positive MECs are clustered in terminal end buds and points of lateral branching, the sites of highest cell proliferation (Silberstein et al. 1996; Zeps et al. 1999). To obtain a clearer picture it will be necessary to perform precise colocalization experiments at different developmental stages and in the available models with impaired mammary development. Clearly PR-positive cells proliferate in hormone dependent tumors and demonstrate that Wnt is probably an autocrine signal. It is possible that distinct signaling mechanisms exist and that at some stage of tumor progression a transition occurs from paracrine to autocrine signaling.

The family of Wnt proteins probably composes only one arm of proliferative signals. Others include epider-

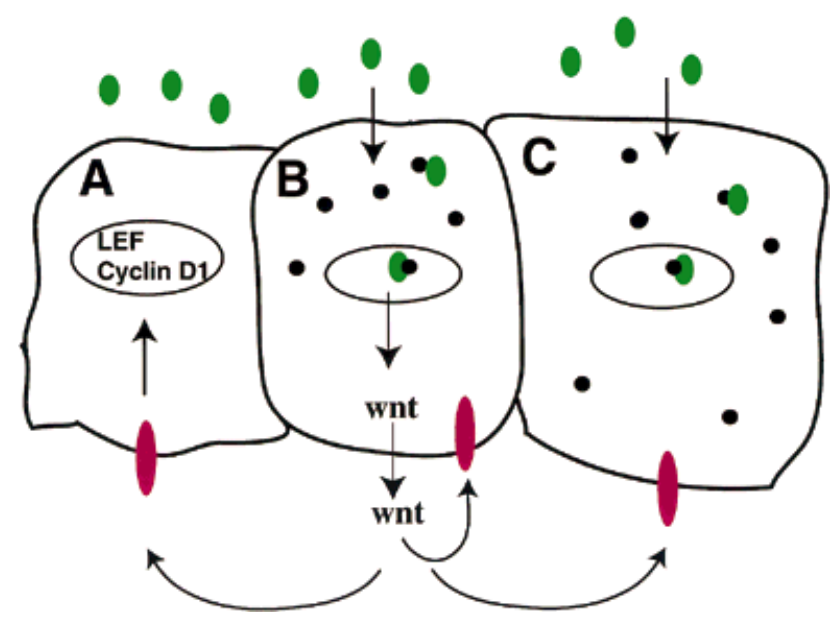

Figure 2. Progesterone-Wnt-induced paracrine/autocrine signaling in MECs. Progesterone (green ovals) activates Wnt-4 gene expression in PR-positive (black dots) cells. Wnt-4 is secreted, binds to the frizzled (Fz) receptor (red ovals) and activates the $\beta$-catenin pathway, which culminates in the activation of the transcription factor LEF. The cyclin D1 gene is a direct target of progesterone. Two distinct models of progesterone-mediated cell proliferation have been proposed. In one model $(A)$ progesterone will promote cell proliferation through Wnts and other growth signals in PR-negative $(A)$ and PR-positive $(B$ and $C)$ cells. In the Seagroves model (Seagroves et al. 2000), progesterone-induced cell proliferation during normal ductal development is limited to PR-negative cells $(A)$. However, it is clear that tumor cells will proliferate independently of their PR status. mal growth factor (EGF) family members (Luetteke et al. 1999) and signals mediated by the prolactin receptor (Ormany et al. 1997; Brisken et al. 1999) and Stat5a (Liu et al. 1997) as evidenced by the phenotype of their respective gene knockout. In vitro results with mammary cell lines also suggest that progesterone synergizes with other growth factor signaling pathways to promote cell growth (for review, see Lange et al. 1999). We anticipate that the rapid accumulation of new knockout models will help to dissect and integrate the contribution of these different pathways to normal development and carcinogenesis.

\section{References}

Bradbury, J.M., P.A. Edwards, C.C. Niemeyer, and T.C. Dale. 1995. Wnt-4 expression induces a pregnancy-like growth pattern in reconstituted mammary glands in virgin mice. Dev. Biol. 170: 553-563.

Brisken, C., S. Park, T. Vass, J.P. Lydon, B.W. O'Malley, and R.A. Weinberg. 1998. A paracrine role for the epithelial progesterone receptor in mammary gland development. Proc. Natl. Acad. Sci. 95: 5076-5081.

Brisken, C., S. Kaur, T.E. Chavarria, N. Binart, R.L. Sutherland, R.A. Weinberg, P.A. Kelly, and C.J. Ormandy. 1999. Prolactin controls mammary gland development via direct and indirect mechanisms. Dev. Biol. 210: 96-106.

Brisken, C., A. Heineman, T. Chavarria, B. Elenbaas, J. Tan, S.K. Dey, J.A. McMahon, and R.A. Weinberg. 2000. Essential function of Wnt-4 in mammary gland development downstream of progesterone signaling. Genes \& Dev. 14: 650-654.

Buhler, T.A., T.C. Dale, C. Kieback, R.C. Humphreys, and J.M. Rosen. 1993. Localization and quantification of Wnt-2 gene expression in mouse mammary development. Dev. Biol. 155: 87-96.

Cadigan, K.M. and R. Nusse. 1997. Wnt signaling: A common theme in animal development. Genes \& Dev. 11:32863305.

Dale, T.C. 1998. Signal transduction by the Wnt family of ligands. Biochem. J. 329: 209-223.

DeOme, K.B., L.J. Faulkin, Jr., H.A. Bern, and P.E. Blair. 1959. Development of mammary tumors from hyperplastic alveolar nodules transplanted into gland-free mammary fat pads of female C3H mice. Cancer Res. 19: 515-520.

Edwards, P.A. 1998. Control of the three-dimensional growth pattern of mammary epithelium: role of genes of the Wnt and erbB families studied using reconstituted epithelium. Biochem. Soc. Symp. 63: 21-34.

Fantl, V., G. Stamp, A. Andrews, I. Rosewell, and C. Dickson. 1995. Mice lacking cyclin D1 are small and show defects in eye and mammary gland development. Genes \& Dev. 9: 2364-2372.

Gavin, B.J. and A.P. McMahon. 1992. Differential regulation of the Wnt gene family during pregnancy and lactation suggests a role in postnatal development of the mammary gland. Mol. Cell. Biol. 12: 2418-2423.

Halban, J. 1900. Die innere Sekretion von Ovarium und Placenta und ihre Bedeutung fuer die Function der Milchdruese. Mschr. Geburtsh. Gynaek. 12: 496-503.

He, T.C., A.B. Sparks, C. Rago, H. Hermeking, L. Zawel, L.T. da Costa, P.J. Morin, B. Vogelstein, and K.W. Kinzler. 1998. Identification of c-MYC as a target of the APC pathway. Science 281: 1509-1512.

Hennighausen, L. and G.W. Robinson. 1998. Think globally, act 
locally: the making of a mouse mammary gland. Genes \& Dev. 12: 449-455.

Horseman, N.D., W. Zhao, E. Montecino-Rodriguez, M. Tanaka, K. Nakashima, S.J. Engle, F. Smith, E. Markoff, and K. Dorshkind. 1997. Defective mammopoiesis, but normal hematopoiesis, in mice with a targeted disruption of the prolactin gene. $E M B O J$. 16: 6926-6935.

Huguet, E.L., J.A. McMahon, A.P. McMahon, R. Bicknell, and A.L. Harris. 1994. Differential expression of human Wnt genes 2, 3, 4, and 7B in human breast cell lines and normal and disease states of human breast tissue. Cancer Res. 54: $2615-2621$.

Humphreys, R.C. and J.M. Rosen. 1997. Stably transfected HC11 cells provide an in vitro and in vivo model system for studying Wnt gene function. Cell Growth Differ. 8: 839-849.

Kordon, E. C. and G.H. Smith. 1998. An entire functional mammary gland may comprise the progeny from a single cell. Development 125: 1921-1930.

Lane, T.F. and P. Leder. 1997. Wnt-10b directs hypermorphic development and transformation in mammary glands of male and female mice. Oncogene 15: 2133-2144.

Lange, C.A, J.K. Richer, and K.B. Horwitz. 1999. Hypothesis: Progesterone primes breast cancer cells for cross-talk with proliferative and antiproliferative signals. Mol. Endocrinol. 13: 829-836.

Liu, X., G.W. Robinson, K.-U. Wagner, L. Garrett, A. WynshawBoris, and L. Hennighausen. 1997. Stat5a is mandatory for adult mammary gland development and lactogenesis. Genes \& Dev. 11: 179-186.

Luetteke, N. C., T.H. Qiu, S.E. Fenton, K.L.Troyer, R.F. Riedel, A. Chang, and D.C. Lee. 1999. Targeted inactivation of the EGF and amphiregulin genes reveals distinct roles for EGF receptor ligands in mouse mammary gland development. Development 126: 2739-2750.

Lydon, J.P., F.J. DeMayo, C.R. Funk, S.K. Mani, A.R. Hughes, C.A. Montgomery, G. Shyamala, O.M. Conneely, and B.W. O'Malley. 1995. Mice lacking progesterone receptor exhibit pleiotropic reproductive abnormalities. Genes \& Dev. 9: 2266-2278.

Moon, R.T., J.D. Brown, and M. Torres. 1997. WNTs modulate cell fate and behavior during vertebrate development. Trends Genet. 13: 157-162.

Nandi, S. 1958. Endocrine control of mammary-gland development and function in the $\mathrm{C} 3 \mathrm{H} / \mathrm{HeCrgl}$ mouse. J. Natl. Cancer Inst. 21: 1040-1051.

Nusse, R. 1999. WNT targets. Repression and activation. Trends Genet. 15: 1-3.

Nusse, R. and H.E. Varmus. 1982. Many tumors induced by the mouse mammary tumor virus contain a provirus integrated in the same region of the host genome. Cell 31: 99-109. . 1992. Wnt genes. Cell 69: 1073-1087.

Olson, D.J. and J. Papkoff. 1994. Regulated expression of Wnt family members during proliferation of C57mg mammary cells. Cell Growth Differ. 5: 197-206.

Ormandy, C.J., A. Camus, J. Barra, D. Damotte, B. Lucas, H. Buteau, M. Edery, N. Brousse, C. Babinet, N. Binart, and P.A. Kelly. 1997. Null mutation of the prolactin receptor gene produces multiple reproductive defects in the mouse. Genes \& Dev. 11: 167-177.

Parkin, N.T., J. Kitajewski, and H.E. Varmus. 1993. Activity of Wnt-1 as a transmembrane protein. Genes \& Dev. 7: 21812193.

Robinson, G.W., P.F. Johnson, L. Hennighausen, and E. Sterneck. 1998. The C/EBP $\beta$ transcription factor regulates epithelial cell proliferation and differentiation in the mammary gland. Genes \& Dev. 12: 1907-1916.
Robinson, G.W., D. Accili, and L. Hennighausen. 2000. Rescue of mammary epithelium of early lethal phenotypes by embryonic mammary gland transplantation as exemplified with insulin receptor null mice. In Methods in mammary gland biology and breast cancer research (ed. M. Ip and B. Asch), (In press). Kluver Academic/Plenum Press. New York, NY.

Schryver, B., L. Hinck, and J. Papkoff. 1996. Properties of Wnt-1 protein that enable cell surface association. Oncogene 13: $333-342$.

Seagroves, T.N., S. Krnacik, B. Raught, J. Gay, B. BurgessBeusse, G.J. Darlington, G. and J.M. Rosen. 1998. C/EBP $\beta$, but not $\mathrm{C} / \mathrm{EBP} \alpha$, is essential for ductal morphogenesis, lobuloalveolar proliferation, and functional differentiation in the mouse mammary gland. Genes \& Dev. 12: 1917-1928.

Seagroves, T.N., J.P. Lydon, R.C. Hovey, B.K. Vonderhaar, and J.M. Rosen. 2000. C/EBP $\beta$ (CCAAT/enhancer binding protein) controls cell fate determination during mammary gland development. Mol. Endocrin. 14: 359-368.

Shyamala, G., X. Yang, G. Silberstein, M.H. Barcellos-Hoff, and E. Dale. 1998. Transgenic mice carrying an imbalance in the native ratio of $\mathrm{A}$ to $\mathrm{B}$ forms of progesterone receptor exhibit developmental abnormalities in mammary glands. Proc. Natl. Acad. Sci. 95: 696-701.

Sicinski, P., J.L. Donaher, S.B. Parker, T. Li, A. Fazeli, H. Gardner, S.Z. Haslam, R.T. Bronson, S.J. Elledge, and R.A. Weinberg. 1995. CyclinD1 provides a link between development and oncogenesis in the retina and breast. Cell 82: 621-630.

Silberstein, G.B., K. Van Horn, G. Shyamala, and C.W. Daniel. 1996. Progesterone receptors in the mouse mammary duct: distribution and developmental regulation. Cell Growth Differ. 7: 945-952.

Stark, K., S. Vainio, G. Vassileva, and A.P. McMahon. 1994. Epithelial transformation of metanephric mesenchyme in the developing kidney regulated by Wnt-4. Nature 372: 679683.

Topper, Y.J. and C.S. Freeman. 1980. Multiple hormone interactions in the developmental biology of the mammary gland. Physiol. Rev. 60: 1049-1056.

Tsukamoto, A.S., R. Grosschedl, R.C. Guzman, T. Parslow, and H.E. Varmus. 1988. Expression of the int-1 gene in transgenic mice is associated with mammary gland hyperplasia and adenocarcinomas in male and female mice. Cell 55: 619625 .

Weber-Hall, S.J., D.J. Phippard, C.C. Niemeyer, and T.C. Dale. 1994. Developmental and hormonal regulation of Wnt gene expression in the mouse mammary gland. Differentiation 57: 205-214.

Wong, G.T., B.J. Gavin, and A.P. McMahon. 1994. Differential transformation of mammary epithelial cells by Wnt genes. Mol. Cell Biol. 14: 6278-6286.

Xu, X., K.-U. Wagner, D. Larson, Z. Weaver, C. Li, T. Ried, L. Hennighausen, A. Wynshaw-Boris, and C.X. Deng. 1999. Conditional mutation of Brcal in mammary epithelial cells results in blunted ductal morphogenesis and tumour formation. Nat. Genet. 22: 37-43.

Zeps, N., J.M. Bentel, J.M. Papadimitriou, and H.J. Dawkins. 1999. Murine progesterone receptor expression in proliferating mammary epithelial cells during normal pubertal development and adult estrous cycle: Association with ER $\alpha$ and ER $\beta$ status. J. Histochem. Cytochem. 47: 1323-1330. 


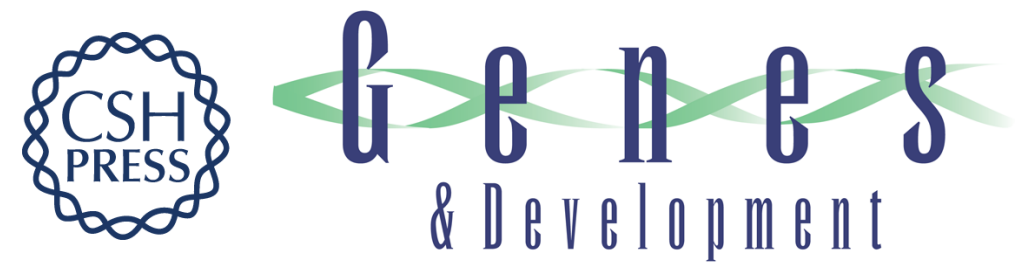

\section{Side-branching in the mammary gland: the progesterone-Wnt connection}

Gertraud W. Robinson, Lothar Hennighausen and Peter F. Johnson

Genes Dev. 2000, 14:

Access the most recent version at doi:10.1101/gad.14.8.889

\section{Supplemental http://genesdev.cshlp.org/content/suppl/2000/05/03/14.8.889.DC1 Material}

References This article cites 42 articles, 22 of which can be accessed free at: http://genesdev.cshlp.org/content/14/8/889.full.html\#ref-list-1

\section{License}

Email Alerting

Receive free email alerts when new articles cite this article - sign up in the box at the top Service right corner of the article or click here.

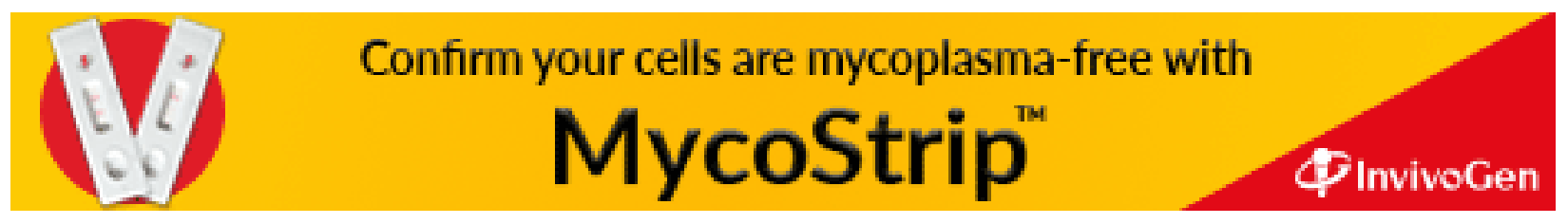

